Brit. J. vener. Dis. (1959), 35, 245.

\title{
FEMALE CONSORTS OF MEN WITH NON-GONOCOCCAL URETHRITIS*
}

\author{
BY \\ N. ROSEDALE \\ St. Mary's Hospital, Paddington, London, W.2
}

It is generally accepted that non-gonococcal urethritis (NGU) is related to sexual intercourse and it has become the usual practice to examine the female consort.

The objects of this present study were:

(1) To obtain further information on the social aspects of the condition.

(2) To compare the clinical findings in these female consorts (within the limits of routine examination).

(3) To assess, if possible, the value of such routine examination.

(4) To determine the effect of treating the female on the subsequent relapse or re-infection of her husband or regular sexual partner.

\section{Present Study}

The case records of 150 consecutive female patients who attended the Special Clinic of St. Mary's Hospital as contacts of men with NGU were studied.

Examination.-The patients were asked for details of symptoms, menstrual history, pregnancies, and sexual contacts. The replies are analysed in Table I.

The clinical examination consisted of a general inspection and the taking of smears and cultures from urethra and cervix. A wet film of any vaginal discharge was examined by dark-ground microscopy. A sample of blood was taken for Wassermann reaction and V.D.R.L. tests. Some of the patients in this group were subjected to special investigations (skin tests, cervical cultures, blood tests, etc.) by Dr. G. W. Csonka for the Medical Research Council study of NGU. Conclusions are not yet available and have not therefore influenced the management of such cases.

\footnotetext{
* Received for publication March 23, 1959.
}

TABLE I

ANALYSIS OF CHARACTERISTICS OF 150 FEMALE PATIENTS

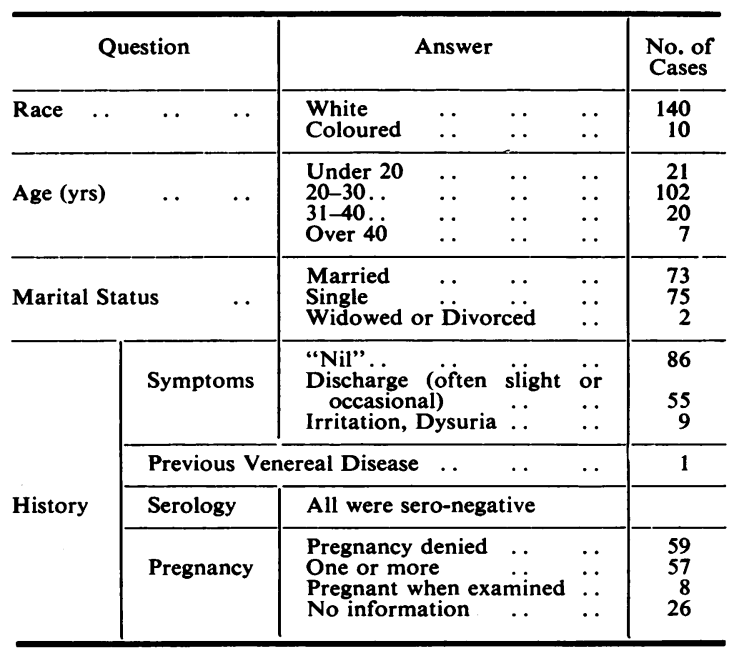

The results may be tabulated as follows:

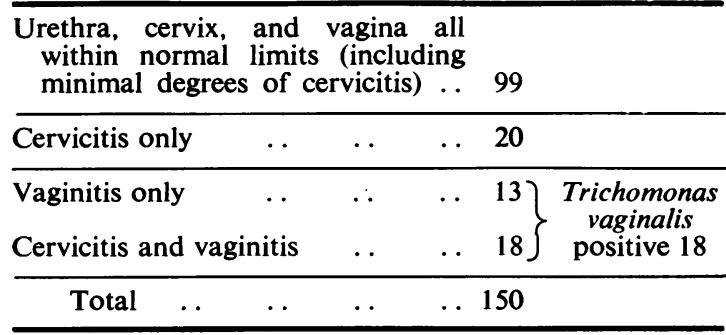

Treatment.-There was no definite routine in the treatment of these female consorts. In the earlier cases no treatment was given to patients in whom 
no clinical abnormality was found, and minimal degrees of cervicitis which were asymptomatic were ignored. Vaginitis or cervicitis was, of course, usually treated by local methods only. Recently, it has become customary to offer treatment to all such consorts and this has usually taken the form of a course of treatment similar to that which cured the male partner, any necessary local treatment being given in addition.

The treatment schedules employed were as follows:

(1) Local Treatment.- Vaginal pessaries, either acetarsol (Stovarsol) or "Penotrane" (Ward, Blenkinsop, and Co.), were prescribed for courses of 1 or 2 weeks. Further treatment with pessaries was usually advised during one or two subsequent menstrual periods.

(2) Streptomycin.-1g. by intramuscular injection once daily for 3 or 5 days.

(3) Penicillin.-1,200,030 units procaine penicillin.

(4) Aureomycin, Terramycin, Achromycin.-0.25 g. four times daily for 4 or 5 days.

(5) Streptomycin and Sulphonamides.-1 g. streptomycin by intramuscular injection, and Sulphatriad or sulphadiazine $1 \mathrm{~g}$. four times daily for 5 days.

The number of female consorts treated may be summarized as follows:

(1) Twelve (8 per cent.), who showed no significant abnormality on examination, were given no treatment.

(2) 23 (15.3 per cent.), who showed some degree of vaginitis (Trichomonas vaginalis positive or negative) or cervicitis, were given local treatment with vaginal pessaries.

(3) 79 (52.6 per cent.) were given courses of treatment usually similar to that of the male consort.

(4) 36 (24 per cent.) were given similar courses of treatment plus vaginal pessaries for local use.

Local conditions appeared to respond (or relapse) in the usual way. In the absence of any specific cause of NGU no specific "tests of cure" could be undertaken.

Follow-up.-Patients treated for any local abnormality were always asked to attend for routine follow-up and any necessary re-treatment. Their progress was usually normal and comparable with that of other patients attending for treatment of similar conditions not associated with urethritis in the sexual partner or partners. No attempt was, therefore, made to evaluate the results of such treatment. In the majority of patients no abnormality was detected at the first examination. After routine smears, cultures, and blood tests (to exclude gonorrhoea, and syphilis) had been found negative and any planned course of treatment had been completed, there appeared to be no need for further visits to the clinic. In all cases the subsequent progress of the male consort was considered to be the best indication of the efficiency of treatment of the female. All females were asked to attend the clinic again in the event of a further episode of urethritis in the consort.

\section{Male Patients}

The clinic records of the male patients with NGU of whom these female patients were the consorts were also studied, and the males were classified as follows:

(1) 102 (68 per cent.) were husbands or regular consorts.

(2) 33 (22 per cent.) were described in their case histories as "promiscuous" and were therefore excluded.

(3) Fifteen (10 per cent.) had no case notes available. (Either they had been destroyed or the patient had been transferred to another clinic.)

Recurrence in the Male.-The recurrence rate in the marital or "regular" consorts was $21 \cdot 6$ per cent. Excluding the consorts of females who were not treated or who were given local treatment only, recurrences occurred in nineteen out of 83 men (22.9 per cent.). These figures do not take into consideration the original treatment of the males, all of whom had previously received some form of treatment. The schedules of treatment of both males and females and the relapse rate in males is shown in Table II.

A high proportion of the male consorts were husbands or "regular" partners (57 marital and 45 "regular" out of $150=68$ per cent.), but eighteen (17.6 per cent.) of the 102 had admitted intercourse with another female, and the time interval between this intercourse and the onset of urethritis varied between 7 months and 1 week (average 8 weeks).

A relapse or re-infection with non-gonococcal urethritis was suffered by $22(21 \cdot 6$ per cent.) of these males. One denied any subsequent intercourse, and the other 21 admitted intercourse with wife or regular consort only. Of these women, all but two had received some form of treatment.

The interval between the first treatment and the recurrence of NGU in the male varied between 15 months and 2 weeks, although in twelve cases ( $54 \cdot 5$ per cent.) the interval was from 4 to 8 weeks. 
TABLE II

FEMALE TREATMENT GROUPS AND RECURRENCE OF NGU IN REGULAR MALE CONSORTS

\begin{tabular}{|c|c|c|c|c|c|c|}
\hline \multirow[t]{2}{*}{ Treatment of Female } & \multicolumn{2}{|c|}{$\begin{array}{l}\text { Female } \\
\text { Patients }\end{array}$} & \multicolumn{2}{|c|}{$\begin{array}{l}\text { Regular } \\
\text { Male } \\
\text { Consorts }\end{array}$} & \multicolumn{2}{|c|}{$\begin{array}{c}\text { Male } \\
\text { Relapses }\end{array}$} \\
\hline & No. & $\begin{array}{l}\text { Per } \\
\text { cent. }\end{array}$ & No. & $\begin{array}{c}\text { Per } \\
\text { cent. }\end{array}$ & No. & $\begin{array}{l}\text { Per } \\
\text { cent. }\end{array}$ \\
\hline None... & 12 & $8 \cdot 0$ & 6 & $50 \cdot 0$ & 2 & $33 \cdot 3$ \\
\hline Local Treatment Only & 23 & $15 \cdot 3$ & 13 & $56 \cdot 5$ & 1 & $7 \cdot 7$ \\
\hline $\begin{array}{l}\text { Streptomycin or Peni- } \\
\text { cillin } \quad . .\end{array}$ & 5 & $3 \cdot 3$ & 5 & $100 \cdot 0$ & 1 & $20 \cdot 0$ \\
\hline $\begin{array}{c}\text { Aureomycin, Terra- } \\
\text { mycin, or Achro- } \\
\text { mycin }\end{array}$ & 51 & $34 \cdot 0$ & 39 & $76 \cdot 5$ & 10 & $25 \cdot 6$ \\
\hline$\underset{\text { phonamides }}{\text { Streptomycin }}+\underset{\text { Sul- }}{.}$ & 23 & $15 \cdot 3$ & 14 & $60 \cdot 9$ & 1 & $7 \cdot 1$ \\
\hline $\begin{array}{l}\text { Aureo., Terra., or } \\
\text { Achro. + Pessaries }\end{array}$ & 20 & $13 \cdot 3$ & 13 & $65 \cdot 0$ & 1 & $7 \cdot 7$ \\
\hline $\begin{array}{ccc}\text { Strept. or } & \text { Pen. + Pes- } \\
\text { saries } & \ldots & .\end{array}$ & 7 & $4 \cdot 6$ & 4 & $57 \cdot 1$ & 2 & $50 \cdot 0$ \\
\hline $\begin{array}{c}\text { Strept. + Sulpha. } \\
\text { Pessaries }\end{array}$ & 9 & $6 \cdot 0$ & 8 & $88 \cdot 8$ & 4 & $50 \cdot 0$ \\
\hline Total & 150 & $100 \cdot 0$ & 102 & $68 \cdot 0$ & 22 & $21 \cdot 6$ \\
\hline
\end{tabular}

Trichomonas vaginalis was found in eighteen (12 per cent.) of the females and in only two $(1.5$ per cent.) of the men.

\section{Discussion}

The various theories concerning the origin of non-gonococcal urethritis may be summarized as follows:

(a) That there is a direct infection of the male urethra during sexual intercourse with an agent as yet unidentified (possibly a virus or pleuropneumonia-like organism), so that the infection is comparable with gonorrhoea. Infestation with Trichomonas vaginalis would presumably come under this heading.

(b) That the urethra is hypersensitive to some common but not necessarily universal inhabitant of the female genital tract. This could explain the phenomenon, in some men with two or more regular female consorts, of repeated recurrence of NGU after intercourse with certain of these women and not with others. It could also explain the sudden onset of the condition after some months or years of marriage when there has been no extra-marital contact by either partner. Harkness (personal communication) has found that condom-protected intercourse in such marital cases avoids a return of the condition. He finds that a relapse rate is high when unprotected intercourse is resumed even after an interval of some months. (c) That the urethritis is secondary to a chronic prostatitis. This prostatitis may be "functional", in that it is due to chronic engorgement and is unrelated to a venereally-acquired infection. Ambrose and Taylor (1953), considering the causes and treatment of NGU, concluded that it was "a disease of sexually active people, but it has not been proved to be venereal in origin and should not be so classified". Graham (1954) considered that "it is questionable that urethritis or chronic prostatitis due to organisms other than $N$. gonorrhoea is the result of infection transmitted through sexual intercourse, although the possibility exists".

When a venereal origin is assumed, a wife or regular partner appears to be involved in a high proportion of cases when compared with recognized venereal diseases. Willcox (1953) found that a casual consort was given as the source of 60 per cent. of cases of gonorrhoea, but of only 40 per cent. of cases of NGU. He concluded that "a wife or regular consort was nominated more often as the source of infection with NGU than with gonorrhoea".

In Great Britain the condition is usually treated in venereal disease clinics, and although the absence of any specific cause obviously limits the investigation of female consorts, King (1955) has stressed the importance of their examination and treatment.

A venereal cause of NGU seems likely, and examination of the female is therefore reasonable. However, some consideration should be given to the domestic upheaval which may be caused by such an examination when neither partner admits extramarital intercourse. This factor cannot be presented in the form of figures or percentages but nevertheless exists.

\section{Summary and Conclusions}

The case records of 150 female patients who attended the Special Clinic at St. Mary's Hospital as the consorts of male patients with non-gonococcal urethritis (NGU) have been examined. Where possible each one has been compared with the record of the male consort.

The relationship between male and female was shown to be marital or "regular" in 102 (68 per cent.). Of these 102 couples, recent intercourse with another partner was denied by 84 ( 56 per cent.).

Routine clinical examination of the female revealed no obvious evidence of genital inflammation in 99 (66 per cent.). However, a similar lack of naked-eye evidence of inflammation is not uncommon in women with gonorrhoea. 
Ignorance of the specific cause of NGU and the absence of any common clinical findings in the female have made it impossible to come to any definite conclusion concerning the results of treatment of female consorts. However, a follow-up of the records of the regular male consorts of treated females shows a recurrence rate of nineteen out of 83 men $(22.9$ per cent). This figure is comparable with the general recurrence rate of NGU when the female consort is not treated.

Although contrary opinions have been quoted, it is difficult to imagine that NGU in the male is not in some way related to sexual intercourse. The incidence in married men who deny any recent extramarital intercourse and the comparatively high recurrence rate may suggest that the mechanism of the condition is more complicated than the straightforward transmission of an infective agent.

The continued examination of female consorts in an attempt to determine any cause for NGU is justified, but, in this series, empirical treatment of the female did not appear to influence the recurrence rate of NGU in the male.

\section{REFERENCES}

Ambrose, S. S., and Taylor, W. W. (1953). Amer. J. Syph., 37, 501. Graham, R. S. (1954). Ibid., 38, 599.

King, A. J. (1955). Med. Press, 234, 101.

Willcox, R. R. (1953). Sth Afr. med. J., 27, 1132. 